\section{Creatine clearance in anorexia nervosa}

We read with interest the recent article by Boag et al $^{1}$ concerning abnormally low creatinine clearance in untreated patients with anorexia nervosa. From their data the authors assumed that these patients had a reversible impairment of renal function. We, however, offer an alternative explanation for the low creatinine clearance.

In normal subjects creatinine clearance calculated from the serum and 24 hour urinary creatinine measured by the Jaffe reaction closely approximates the glomerular filtration rate. This close approximation, however, is due to two compensating errors: firstly, in normal subjects $2-3 \mathrm{mmol}$ $(0.23-0.34 \mathrm{~g})$, representing $20-30 \%$ of the urinary creatinine, is from tubular secretion rather than glomerular filtration; and secondly, $15-35 \mu \mathrm{mol} / \mathrm{l}(0.17-0.40$ $\mathrm{mg} / 100 \mathrm{ml}$ ), representing $15-30 \%$ of the serum creatinine as measured by conventional Jaffe methods, is from noncreatinine chromogens. ${ }^{2}$ Less than $5 \%$ of urinary creatinine measured by the Jaffe reaction is due to these non-creatinine chromogens. ${ }^{2}$ The two errors cancel each other on calculation of creatinine clearance, as one is in the numerator and the other is in the denominator of the clearance equation.

In various pathological conditions the relative magnitude of these errors no longer quantitatively compensate each other, and creatinine clearance becomes a poor predictor of glomerular filtration rate. In severe renal failure creatinine clearance gives a significant overestimate of the glomerular filtration rate. Although tubular secretion still accounts for $20-30 \%$ of urinary creatinine, serum non-creatinine chromogens still account for only 15$35 \mu \mathrm{mol} / \mathrm{l}(0.17-0.40 \mathrm{mg} / 100 \mathrm{ml})$ of the serum creatinine (Jaffe reaction) and now represent $<5 \%$ of the total serum creatinine. ${ }^{3}$ In patients with low muscle mass who have low serum and 24 hour urinary creatinine creatinine clearance gives a significant underestimate of the glomerular filtration rate. In these patients the Jaffe reaction still measures urinary creatinine relatively accurately, but now the noncreatinine chromogens in the serum may represent $50 \%$ or more of the serum creatinine (measured by Jaffe reaction). A particularly dramatic case, which we encountered several years ago, was a woman weighing $45 \mathrm{~kg}$ with congenital anterior horn cell disease and severe wasting of the muscles. Her 24 hour urinary creatinine was only $1.2 \mathrm{mmol} / \mathrm{l}(136 \mathrm{mg})$ and her serum creatinine was $35 \mu \mathrm{mol} / \mathrm{l}$ $(0.040 \mathrm{mg} / 100 \mathrm{ml})$ by a Jaffe method, yielding a creatinine clearance of $25 \mathrm{ml} / \mathrm{min}$. Her serum urea concentration was normal at $3.9 \mathrm{mmol} / \mathrm{l} \quad(23 \mathrm{mg} / 100 \mathrm{ml})$. Her creatinine clearance was artefactually low because non-creatinine chromogens accounted for $>60 \%$ of her serum creatinine measured with the Jaffe reaction, and her renal function was normal.

Among the principal non-creatinine chromogens that react to a Jaffe method in serum are various ketoacids. ${ }^{2}$ In patients with diabetic ketoacidosis ${ }^{4}$ and a normal fasting subject ${ }^{5}$ raised acetoacetate concentrations cause spurious increases of serum creatinine measured by the Jaffe method and thus spuriously low creatinine clearances. With prolonged starvation as seen with anorexia nervosa relatively severe ketosis would be expected. ${ }^{6}$ Consequently, the serum Jaffe creatinine would be artefactually high. In the work reported by Boag et al sera for creatinine determinations were collected at $800 \mathrm{am}$. How long the patients had been fed a high energy diet before the "before treatment" creatinine clearances were determined is not clear. Even if the patients had been fed for several days, however, with their severely depleted muscle mass and lack of gluconeogenic substrates they might have become reasonably ketotic with fasts lasting as little as one night. If ketosis did occur serum creatinine measured with the Jaffe reaction would have been artefactually high, and this would contribute to the artefactual lowering of the creatinine clearance. Consequently, without more reliable measurements of glomerular filtration rates, such as inulin clearance, in at least some patients, or documentation of the absence of serum ketones, low creatinine clearance measured by Jaffe methods in patients with untreated anorexia nervosa should not be assumed to indicate renal dysfunction.

JH ECKFELDT EF FREIER

Department of Laboratory Medicine and Pathology, University of Minnesota Hospitals, Minneapolis, MN 55455

United States

\section{References}

${ }^{1}$ Boag F, Weerakoon J, Ginsburg J, Havard CWH, Dandona P. Diminished creatinine clearance in anorexia nervosa: reversal with weight gain. J Clin Pathol 1985;38:60-3.

${ }^{2}$ Murray RL. Creatinine. In: Kaplan LA, Pesce AJ, eds. Clinical chemistry: theory, analysis and correlation. St Louis: CV Mosby, 1984: 1247-53.

${ }^{3}$ Carrie BJ, Golbetz HV, Michaels AS, Mye BB. Creatinine: an inadequate filtration marker in glomerular disease. $\mathrm{Am} \mathrm{J}$ Mez 1980;69:177-82.

4 Molitch ME, Todman E, Hirsch CA, et aD Spurious serum creatinine elevations $\frac{0}{0-0}$ ketoacidose. Ann Intern med 1980;9 280-91.

${ }^{5}$ Mascioli SR, Bantle JP, Freier EF, Hoogwe BJ. Artificial elevation of serum creatinime due to fasting. Arch Intern Med 1984, 144: 1575-6.

- Larner J. Intermediate metabolism and its reguilation. Englewood Cliffs, New Jersey: Prentice-Hall 1971:214-7.

Drs Boag and Dandona reply as follows: ف่ We thank Drs Eckfeldt and Freier fof pointing out the limitations of indices of renal function based on creatinine clearo ance, especially in cases in which the turn over of creatinine is likely to fall and ketogenesis is likely to produce chromogenic reactions that mimic thoserof creatinine.

None of our patients had ketonuria when we began to measure their plasingo creatinine concentration and urinar creatinine excretion. ${ }^{1}$ Whether this was th result of the initial feeding and "stabilisan tion" for 24 to 72 hours, which may supe press lipolysis and ketogenesis, or whethe? such patients have switched off lipolysio and ketogenesis through some othe? metabolic mechanism is not clear at pres? ent. In this context it is worth noting that? patients with anorexia nervosa do not have raised free fatty acid concentrations. ${ }^{23}$ This was also true of a series of patients witk anorexia nervosa whom we investigated? their free fatty acid concentrations ( $565 \mu \mathrm{mol} / \mathrm{l})$ were comparable with those in controls $(654 \mu \mathrm{mol} / \mathrm{l}) .{ }^{4}$ Insulin receptos population is known to be increased in anorexia nervosa; 5 possibly, enhanced sen $\frac{}{0}$ sitivity to insulin may somehow "protect" such patients from lipolysis and ketogenesis. The concentrations of acetoacetate required to cause spurious increases of plasma creatinine concentraê tions are far higher than those expected iw patients with anorexia nervosa.

Finally, we now have data to show that glomerular filtration rate as measured by excretion of edetic acid labelled with ${ }^{51}$ chromium is also greatly diminished ip 
these patients and that it increases with weight gain.

In conclusion, Eckfeldt and Freier have raised an interesting theoretical point regarding the low creatinine clearance in patients with anorexia nervosa. Our patients were, however, not ketotic and therefore Eckfeldt's and Freier's objection is not directly relevant. Furthermore, we are all too aware of the fallacies of basing indices of renal function on creatinine clearance, ${ }^{6}$ and have taken care to show that the true glomerular filtration rate based on clearance of edetic acid labelled with ${ }^{51}$ chromium is also diminished in these patients.

P DANDONA F BOAG

Metabolic Unit, Department of Chemical Pathology and Human Metabolism, Royal Free Hospital, London NW3

\section{References}

' Boag F, Weerakoon J, Ginsburg J, Havard CWH, Dandona P. Diminished creatinine clearance in anorexia nervosa: reversal with weight gain. J Clin Pathol 1985;38:60-3.

${ }^{2}$ Coppen AJ, Gupta RK, Eccleston EG, Wood KH, Wakeling A, De Souza VF. Plasma tryptophan in anorexia nervosa. Lancet 1976;i:961.

${ }^{3}$ Gjesdal $\mathrm{K}$, Nordoy A, Wang $\mathrm{H}$, Bernsten $\mathrm{H}$, Myos OD. Effects of fasting on plasma and platelet free fatty acids and platelet function in healthy males. Thromb Haemost 1976;36: 325-30.

4 Luck P, Mikhailidis DP, Dashwood MR, et al. Platelet hyperaggregability and increased aderenoceptor density on anorexia nervosa. J Clin Endocrinol 1983;57:911-4.

${ }^{5}$ Wachslicht-Rodbard H, Gross HA, Rodbard D, et al. Increased insulin binding to erythrocytes in anorexia nervosa: restoration to normal with refeeding. $N$ Engl $J$ Med 1979; 300: 882-7.

- Fonseca V, Mohiuddin J, Weerakoon J, Mikhailidis DP, Boss M, Dandona P. Plasma creatinine and creatinine clearance in nutritional osteomalacia. Lancet 1984;i: 316-9.

\section{Book reviews}

Pathology of the Lung. Vols 1 and 2. 4th ed. H Spencer. (Pp 1176; £125.) Pergamon Press. 1984.

Fourth editions of text books require little reviewing. Pathology of the Lung is a well known and respected book that is a credit to Professor Spencer and St Thomas's Hospital. It will be attractive to anyone interested in pulmonary pathology, and should be on the shelves of every hospital library. Whether individual pathologists can afford to pay $£ 125$ for a fourth edition when they already have the third is a moot point and will depend on their pulmonophilia.

When I reviewed the third edition I was irritated by the provision of an index in only one volume of a two volume set. This problem has not been rectified in the fourth edition. Perhaps publishers do not read book reviews or perhaps they are too eager to maximise their profits regardless of criticism. Ignore this defect and persuade your library to buy a copy, but if you become annoyed as I do by publishers' parsimony, write an irascible complaining letter to Pergamon Press, so that you irritate them as well. If they have to answer your letter it will cost them money!

G SLAVIN

Electron Microscopy in Human Medicine. Vol 11 (a). The Skin. Ed JV Johannessen and $\mathrm{K}$ Hashimoto. (Pp 343; £57.50.) McGraw-Hill. 1985.

This is the penultimate book in this massive 12 volume series (for some curious reason the last two volumes are to be called 11 (a) and 11 (b) rather than 11 and 12), the format being the same as the earlier volumes Professor Hashimoto is the editor of this volume and there are 11 other contributors, mainly from Japan and the United States. The material of the book consists of well illustrated ultrastructural descriptions of skin pathology under the headings of neoplastic conditions; bullons dermatoses; hereditary ichthyoses; hair abnormalities and viral infections, together with a chapter on the freeze-fracture technique as applied to the skin. No doubt, any institution that has already collected the previous volumes will want to add this one to the set and it will be a valuable reference work for pathologists interested in dermatology What is missing, however, is a clear indication as to the conditions for which electron microscopy is likely to be diagnostically useful and which ultrastructural features are simply of academic interest.

JULIE CROW

Laboratory Manual of Histochemistry. Linda L Vacca. (Pp 596; \$34.) Raven Press. 1984.

This is traditional histological technique in modern guise. Loose leaved, spiral bound, the manual is set in typescript of differing styles and pitch that change haphazardly within the same section or the same page. The illustrations are restricted to line diagrams and a few photographs that lack lustre. Some may feel the title to be pretentious; only one tenth of this book is concerned with enzyme histochemistry, and immunohistochemistry is briefly described in 23 pages. The rest of this book is a manual on tissue preparation, section cutting, and dye staining. Lillie and Puchtler influenced the work of the author and their papers dominate the bibliography.

Overall, this manual is comprehensive and seems to be useful and reliable, but its success on this side of the Atlantic will depend on its ability to rise above the lecture note presentation and suspect staying power in laboratory use.

RAB DRURY

Arthritis and Allied Conditions. Daniel J McCarty. 10th ed. (Pp 1773; US \$121.00.) Lea \& Febiger. 1985.

This new edition to one of the best and most well known major rheumatology textbooks is published six years after its predecessor. Its length, over 1700 pages, permits a comprehensive review of virtually all rheumatological conditions. There are 104 chapters written by over 100 contributors who comprise the best of North American rheumatologists. Unfortunately, the absence of any British, or indeed European contributors, gives a rather too severe American flavour. By any standards, however, this is an excellent synopsis of rheumatic diseases.

The book is well indexed and contains key references within the text. Its outline is similar to the previous edition. It comprises an introductory section on the epidemiology and differential diagnosis of arthritis; a relatively detailed account of some of the scientific pillars of current rheumatological thought; a brief resume on antirheumatic drugs; and then sections on the major rheumatic diseases. The book concentrates on clinical aspects rather than giving detailed accounts of laboratory techniques. For the practising pathologist it will provide an ever ready source of clinical information to place in the context of pathological findings.

It is a book to dip into rather than read exhaustively. I found it simple to review rapidly diverse subjects: for example, can 